\title{
Health Behaviours in Scaffold Use Risk Assessment Model - SURAM
}

\author{
Hubert Bojar ${ }^{1, D}$, Francisco Silveira ${ }^{2, B}$, Mario Rebelo ${ }^{2, B}$, Elżbieta Czarnocka ${ }^{3, B}$, Krzysztof Czarnocki ${ }^{3, C}$ \\ ${ }^{1}$ Institute of Rural Health, Lublin, Poland \\ ${ }^{2}$ CIICESI, ESTG, Politécnico do Porto, Portugal \\ ${ }^{3}$ University of Technology, Lublin, Poland \\ A - Research concept and design, B - Collection and/or assembly of data, C - Data analysis and interpretation, \\ $D$ - Writing the article, E - Critical revision of the article, F - Final approval of article
}

Bojar H, Silveira F, Rebelo M, Czarnocka E, Czarnocki K. Health Behaviours in Scaffold Use Risk Assessment Model - SURAM. Ann Agric Environ Med. 2019; 26(1): 138-142. doi: 10.26444/aaem/100534

\begin{abstract}
Introduction. Problems concerning occupational safety and health are commonly found in the construction industry, including falling materials, tools or people from a height, stepping on objects, and injuries caused by hand tools. An important factor in occupational safety in the construction industry is the use of scaffolds. All scaffolds used in construction, renovation, repair (including isolating, painting and decorating) and demolition, should be erected, maintained and dismantledin accordance with safety procedures. Therefore, it is crucial to deal with the safety of scaffolds and risk assessment in the construction industry; thus, the way of undertaking the assessment and the liability of assessment seems to be essential for professionals. However, it has been found that those professionals are prone to rely heavily on their own experience and knowledge in decision-making regarding risk assessment.

Materials and method. The Scaffold Use Risk Assessment Model (SURAM) has been developed for assessing risk levels at various stages of the construction process in various work trades. The SURAM is the result of a research project carried out at 60 construction sites in Poland and Portugal where 504 observations have been completed including both harmful physical and chemical factors, stress level, workers' habits, as well as a hundreds ex-post reconstruction of construction accidents scenarios.

Results. It was found that the workers' Health Behaviour Index $(\mathrm{HBI})$ seems to be a more direct predictor for development of the unsafe chain of events leading to an accident than the workload, and concentration of harmful factors at the workplace. Conclusions. The developed HBI module of SURAM seems to be beneficial for predicting high-risk construction activities, and thus preventing the occurrence of accidents, based on a set of historical accident data.
\end{abstract}

Key words

health behaviours, risk assessment, work safety.

\section{INTRODUCTION}

The construction industry is a booming sector of the Polish economy; however, according to Eurostat, the European Statistical Office, this branch of industry is classified among the sectors of the economy presenting high occupational risks and an unsatisfactory level of occupational safety. Although some safety programmes have been developed in Poland, the observed accident reduction rate seems to be rather weak. Employees in the construction sector are exposed to biological and chemical factors, as well as to the effects of noise, vibrations, insufficient illumination and temperature. Also, the peak of workload, and especially frequent changes in the level of workload, have been observed in many investigations. More than $45 \%$ of workers in the construction sector state that their work has a negative impact on their health [1]. The construction industry is subject to high occupational risk and high rates of occupational accidents, occupational diseases and absenteeism from work. In Europe, according to Eurostat data for 2011 (for 28 European Union [EU] countries), the fatal accident rate was 6.39 (per 100,000 persons in employment) in the construction industry (Eurostat 2016). The majority of serious accidents

Address for correspondence: Hubert Bojar, Institute of Rural Health in Lublin e-mail: Bojar.Hubert@gmail.com

Received: 16.04.2018; accepted: 06.12.2018; first published:03.01.2019 took place at the scaffolds or at construction sites with scaffolds.

Taking into consideration the frequency of accidents and high occupational risk in the construction industry with scaffold use, it is important to take the necessary steps to reduce this exposure. In these conditions the research project Scaffold Use Risk Assessment Model for Construction Process Safety ('ORKWIZ') has been developed in Poland since early 2016. The project focused on the introduction of a system of new/additional procedures and tools for monitoring safety on construction sites $[2,3,4]$. This system built as a model should impose strict rules regulating the conduct of contractors in a comprehensive manner to ensure the elimination of hazards from the construction site, or an effective reduction of associated risks. The construction of SURAM is the core part of the 'ORKWIZ' project. The research also shows that many accidents can be avoided by developing a proper concept of safety assurance at the preparation stage $[5,6,7]$.

\section{MATERIALS AND METHOD}

Five different regions of Poland were selected for the project research. The regions were selected by virtue of level economic development, unemployment rate, technical 
culture of employees, construction processes intensity, and infrastructure level, among other factors. Accordingly, the study was conducted at different construction sites representing typical (more frequent) scaffold size, scaffold system types and technical equipment. Such a diversity of regions, sites and employee praxis habits and customs is required to achieve a universal safety climate for the proposed safety model. At least 120 construction sites with scaffold use were examined during the period of the research project. Subsequently, a random sampling procedure was conducted to select individual workers at each construction site; 504 individual workers of those sites potentially exposed to occupational hazards were selected in the first two years of the project. For the purpose of the SURAM, 800 individuals were interviewed. An original questionnaire was developed for risk perception and safety climate assessment at the construction site. At the beginning of our investigation, several existing questionnaires were verified, including NOSACQ-50, Quality of Worklife Module (NIOSH), Contractor OH\&S Evaluation, as well as some Polish ones (especially the IZZ questionnaire) and an original tool was prepared better fitted to the occupational environment and construction workers perception of the construction site. Before using the original questionnaire among the selected population, a pilot study was carried out among 60 workers. The trial and first run exploratory factor analysis confirmed that the original 45-item questionnaire could be used as a risk perception and safety climate scale in the Polish construction industry. A 5-point Likert-type scale (1 = strongly disagree, $5=$ strongly agree) was used to collect the workers' responses. Yes/no responses, lists of options, checkthe-box responses, quantity choice, etc., were used to selfreport incident involvement and demographic data. Since the questionnaire used questions and answers based on scales, a not-applicable option for situations in which the respondents did not know how to respond or did not have an opinion on the issue were also added. In order to ensure greater objectivity, both questionnaire and model for increasing flexibility of SURAM, the control group was recruited at construction sites, in Portugal, taking into consideration similarities and differences between the countries (Tab. 1).

The difference in drug use (including alcoholic beverages) between groups seems to be the result of different levels of acceptance of some alcoholic beverages between Polish and Portuguese workers. consumed in the shift period. In the detailed questions regarding type of drug and frequency of use. no significance was found. except for the popularity of beverages containing a high volume of spirits in Poland and wine or beer in Portugal.

Questionnaire validity and reliability. In the implemented version of the questionnaire. the questions focused on six factors: 1) life coherence and social associations (SSOC) 11 questions; sense of control (SLOC) - 10 questions; state of health (SLKZ) - 5 questions; value hierarchy (SLWO) - 11 questions; occupational praxis and psychical attitude (SIZZ) - 10 questions; risk perception (SPR) - 8 questions. There were also 7 predictors not involved in any of the six scales. Sampling adequacy was measured using the KaiserMeyer-Olkin test and the Bartlett's test of sphericity was used to evaluate correlations among safety climate items [8, $9,10]$. Construct validity was tested with exploratory factor analysis and discriminant validity checked by comparing
Table 1. Characteristics of the two groups

\begin{tabular}{lccccc}
\hline \multirow{2}{*}{ Variable } & \multicolumn{2}{c}{ Poland } & \multicolumn{2}{c}{ Portugal } \\
\cline { 2 - 6 } & \multicolumn{2}{c}{ Study group } & Control group & $\mathrm{p}$ \\
\cline { 2 - 6 } & $\boldsymbol{N}$ & $\%$ & $\boldsymbol{N}$ & $\%$ & \\
\hline Monitored subiect & 487 & 100 & 38 & 100 & $>0.05$ \\
\hline Gender & & & & & \\
\hline Male & 482 & 98.3 & 36 & 94.7 & $>0.05$ \\
\hline Female & 5 & 1,7 & 2 & 5,3 & $>0,05$ \\
\hline
\end{tabular}

\begin{tabular}{lccccc}
\hline Construction workers & 345 & & & & \\
\hline Other workers & 88 & & & & \\
\hline Administrarive workers & 17 & 3.7 & 2 & 5.25 & $>0.05$ \\
\hline Managers and Supervisors & 27 & 5.8 & 2 & 5.25 & $>0.05$ \\
\hline Position in Company & 76 & 15.6 & 6 & 15.8 & $>0.05$ \\
\hline 72,8 & 28 & 73.7 & $>0.05$ & 21.05 & $>0.05$ \\
\hline 17,7 & 6 & 15.8 & $>0.05$ & 23.7 & $>0.05$ \\
\hline $45-54$ & 83 & 17.3 & 8 & 21.05 & $>0.05$ \\
\hline$\geq 55$ & 113 & 23 & 7 & 18.4 & $>0.05$ \\
\hline Work experience (years) & & & & & \\
\hline$<1$ & 57 & 11.5 & 4 & 10.5 & $>0.05$ \\
\hline $2-5$ & 153 & 35.8 & 14 & 36.8 & $>0.05$ \\
\hline $6-10$ & 131 & 26.8 & 10 & 26.3 & $>0.05$ \\
\hline $11-20$ & 79 & 13.6 & 5 & 13.2 & $>0.05$ \\
\hline$\geq 21$ & 67 & 12.3 & 5 & 13.2 & $>0.05$ \\
\hline Drug use & 379 & 77.8 & 20 & 52.6 & $>0.05$ \\
\hline Smoking & 401 & 82.3 & 23 & 60.5 & $>0.05$ \\
\hline Accident involvement or witness & 189 & 38.8 & 11 & 28.9 & $>0.05$ \\
\hline
\end{tabular}

the safety climate scores among groups varying in age, work experience, accident involvement, position in the company, education and the type of the organization. To evaluate the internal consistency of the questionnaire, Cronbach's a was used. Speraman-Brown coefficient and $\Omega$. Cronbach's a was used when questions were rated on the 5-point Likert scale; this represented mean correlations among items. Spearman Brown coefficient represented the reliability coefficients that can be obtained from possible combinations of split-half questions. The minimal proposed value of these coefficients was 0.70 . The data obtained using ther questionnaire was analyzed using Statistica 13 StatSoft Inc. Comparison of the difference in accident risk perception and safety climate scores among different demographic groups (age, work experience, occupational experience, position in the company, education, accident involvement, type of construction site) was performed with the multiple analyses of variances (MANOVA). To define questionnaire utility for the final SURAM model, principal component analysis was performed retaining all the factors with Eigen value greater than one. Once the factors were extracted, Varimax rotation was performed. The analyses showed that the Kaiser-MeyerOlkin measure for sampling the adequacy was 0.81 , indicating that these data were appropriate for factor analysis $[11,12$, $13]$, Bartlett's test of sphericity was significant $\left(\chi^{2}=1270.6\right.$. $\mathrm{p}<0.01)$. which indicated that there were correlations among safety climate items and the correlation matrix was not a unit matrix. 


\section{RESULTS}

The reliability of the measurement method depends on its internal consistency. As indicated previously, the consistency was assessed with Cronbach's a, Speraman-Brown coefficient, and $\Omega$. According to Cronbach's $\alpha$, internal consistency was 0.79 for the entire population. Spearman Brown coefficient was 0.78 and $\mathrm{W}=0.70$. Most coefficients were higher than 0.70 and adequate for psychometric requirements for a measurement. Thus. the method for measuring occupational hazards, risk perception and the contractor safety climate was appropriate [14, 15, 16] (Tab. 2, Fig. 1). To make it clearer, it shows only the values of the structural equation, but not the measuring models. With the exception of the questionnaire scales, the SURAM was developed to include monitoring of the workers' psycho-physiological parameters before the shift as well as the part of the shift after a break, corresponding to the workload during the shift (WL). The wide range of demographic factors (DF), collected both at the construction site as well as from local statistical offices, were also used for model construction. Environmental parameters at the construction sites were monitored on two up to three levels of the scaffold (depending on size) during at least a fiveday working week, including sound level, illumination and microclimate (EF). Diversity from the standard levels was then evaluated as the measure for the matrix construction. To evaluate worker visual concentration on the critical areas or elements of the work zone, mobile eye-tracking equipment was used (ET). Stability and quality of scaffold set-up and maintenance was evaluated (Cscaffold), as well as the level construction site organization (CSO).

The complementary element of SURAM, especially for the model teaching period, was the Historical Accident Analysis module (AHA). In this module, accidents from the past 10 years of the construction industry were reduced to the elementary factors. As the model presented at the Figure 1 is a beta model, prepared after first year of the projects, some of the relations could not be calculated precisely. Therefore, even in those partial data it shows potential for use in improving safety at the construction sites using scaffolds.

Table 2. Questionnaire Scales Inter-Consistency Coefficients

\begin{tabular}{ccccc}
\hline Scale & No. of items & Cronbach's a & Spearman-Brown Coefficient & $\Omega$ \\
\hline S(SOC) & 11 & 0.769 & 0.774 & 0.705 \\
\hline S(LOC) & 10 & 0.682 & 0.706 & 0.624 \\
\hline$S($ LKZ) & 5 & 0.631 & 0.693 & 0.628 \\
\hline$S($ LWO $)$ & 11 & 0.895 & 0.899 & 0.811 \\
\hline$S(H B I)$ & 10 & 0.795 & 0.789 & 0.768 \\
\hline$S(R P)$ & 8 & 0.707 & 0.719 & 0.631 \\
\hline
\end{tabular}

S(SOC) - standardized life coherence and social associations; S(LOC) - standardized sense of control; S(LKZ) - standardized health state; S(LWO) - standardized value hierarchy; S(HBI) standardized occupational praxis and psychical attitude; S(RP) - standardized risk perception

Also, according to several authors, the goodness-of-fit (GF) model had to be considered first $[9,17,7,18]$. Within the GF model, it is necessary to consider three indicators: measure of absolute fit, measure of increased fit and measure of decreased fit (Tab. 3) [17, 13, 19]

Due to the absolute correspondence of the models, the indicators that can be applied in an incompetent strategic analysis are GFI (goodness-of-fit index) and the index of corresponding values. In GFI, the higher the value, the higher the correspondence. In this case, the obtained value was 0.92 . This indicator is acceptable since it is over $0.90[20,21]$.

Table 3. Model fit values

\begin{tabular}{ccc}
\hline Statistics & Recommended Values & Achieved Level \\
\hline $\mathrm{X}^{2} / \mathrm{df}$ & $<3.0$ & 2.62 \\
\hline $\mathrm{GFI}$ & $>0.90$ & 0.95 \\
\hline $\mathrm{AGFI}$ & $>0.90$ & 0.94 \\
\hline $\mathrm{NFI}$ & $>0.90$ & 0.96 \\
\hline $\mathrm{CFI}$ & $>0.90$ & 0.94 \\
\hline $\mathrm{IFI}$ & $>0.90$ & 0.93 \\
\hline $\mathrm{RFI}$ & $>0.90$ & 0.95
\end{tabular}

GFI - goodness-of-fit index; AGFI - adjusted goodness-of-fit index; NFI - normed fit index; NNFI - non-normed fit index; CFI - comparative fit index; IFI - incremental fit index; RFI relative fit index.

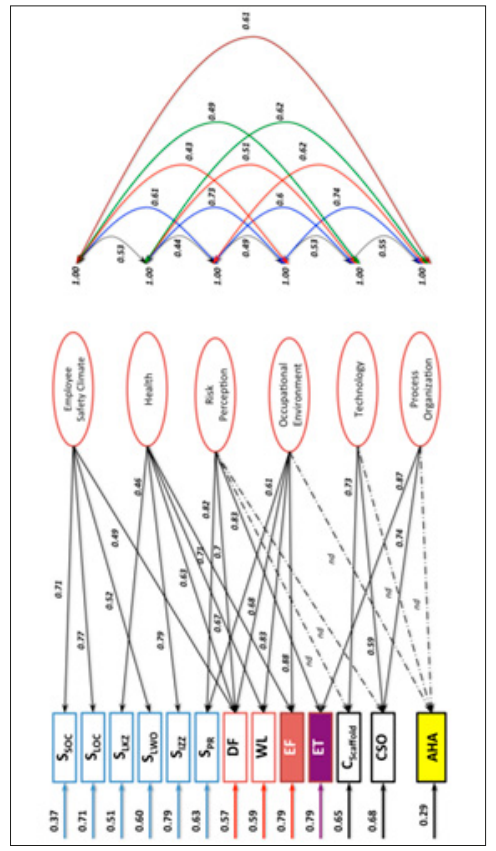

Figure 1. Structural model of SURAM. DF - demographic factors; WL - work load; EF environmental factors; ET - eye tracking; $\mathrm{C}_{\text {scaffold }}$ - scaffold construction; CSO - construction site organization; AHA - historical accidents analysis

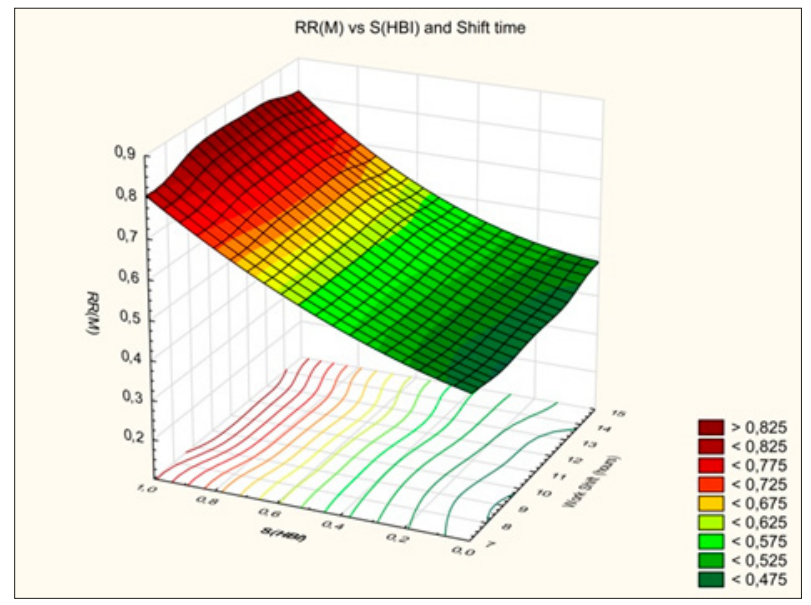

Figure 2. $\mathrm{S}(\mathrm{HBI})$ as main predictor of SURAM. Wilks' $\lambda=0.5316, F(4.638)=59.265 ; p<0.0001$ 
In the presented model, this indicator has the value of 0.9 which, according to the above-mentioned researchers, is an indicator of good correspondence. Table 2 shows intercorrelations among the six scales that were entered into the final model. Because of the comparatively small sample size, each correlation coefficient was significant at 0.05 . As a step in model construction, this research focused on investigating whether there is any significant difference in risk perception and the safety climate in working teams, as well as construction enterprises among the demographic subgroups [22, 23]. Significant differences were observed in demographic subgroups in questionnaire scales; for example: for practicum, there were significant differences on all scales but for education level there were significant differences in (S(SOC), S(LOC), S(HBI) and S(RP) scales, but not for S(LKZ) and $\mathrm{S}(\mathrm{LWO})$ scales. Gender did not influence opinions in questions on analyzed factors, as more than $97 \%$ of employees (94.7\% and $98.3 \%$ in study and control groups, respectively) were male; Because presenting all the results obtained in this study would require too much space, they will therefore be discussed in detail in a subsequent study in which larger subgroups could be observed. At the present stage of the study and project development, it was found that the initial worker stress level (monitored by the bio-physical parameters at the beginning of the shift and after the break + ET) [24] is a more direct predictor for development of an unsafe chain of events leading to an accident than the work load (WL) and concentration of harmful factors (EF) at the workplace [25].

\section{CONCLUSIONS}

A study of risk perception, occupational hazards and the safety climate at construction sites with scaffolds in Poland, as depicted in this study, had never been previously conducted. Therefore, an attempt was made to monitor risk perception, understand the value and beliefs about the safety among Polish workers, or precisely, workers' teams at Polish construction sites, as a growing number of migrant workers (mostly Ukrainians) have been noted during the first stage of the study. Evidence was obtained that the perception of accident risk and the safety climate on Polish construction sites can be reliably measured with a 45 -item questionnaire, involving six factors: life coherence and social associations (SSOC), sense of control (SLOC), state of health (SLKZ), value hierarchy (SLWO), occupational praxis and psychical attitude (SIZZ) and risk perception (SPR). The previous research results indicated that construction workers placed more emphasis on safety training, organizational environment, safety awareness and competency, and management support. Although the previous study remains valid, the current study shows that initial stress level could be crucial for developing situation risky or potentially prone to accident.

To establish a general model SURAM, the subjects came from several economically, historically and technologically diversified Polish regions, while the control group came from Portugal. Thus, the developed 45-item questionnaire can be used as a safety measurement tool for the whole construction sector using scaffolding. This tool was based on the results from different parts of the world and then modified to fit Polish construction sites. Further research will focus on a structural equation model which will result from the structural analysis presented in this study. Additional factors: demographic factors (DF), work load (WL), environmental factors (EF), eye tracking (ET), construction of scaffold (Cscaffold), construction site organization (CSO), and historical accidents analysis (AHA) will have to be included. Thist will determine the workers' attitudes towards the risk level at their workplace, hazardous situations and real occupational accidents that took place there. Subsequently. the six factors from this study will be used to develop a hypothetical frame of the SURAM model. Additionally, as already indicated, each demographic subgroup had strong influence on some of the six factors. This will be analyzed in detail and discussed in the next stages of the study. Currently, workers from six regions, including Portugal, were involved; therefore, the level of technical culture and type of organization was one of the variables (CSO) investigated. Consequently, in the future, the influence of this variable on all six scales will be studied. The prognostic validity of the SURAM model developed in the current study will be assessed in the subsequent stages. The results obtained will have practical value for occupational health prevention in the construction sector. The developed standardized occupational praxis and psychical attitude - S(HBI) - as the main predictor of SURAM, even at this initial stage are found to be useful for predicting high-risk construction activities and thus preventing the occurrence of accidents, based on a set of historical accident data.

\section{REFERENCES}

1. Dabrowski A. An investigation and analysis of safety issues in Polish small construction plants. Int J Occup Saf Ergon. 2015; 21(4): 498-511. doi:10.1080/10803548.2015.1085206.

2. Forteza FJ, Carretero-Gómez JM, Sesé A. Occupational risks. accidents on sites and economic performance of con-struction firms. Safety Sci. 2017; 94: 61-76.

3. Törner M, Pousette A. Safety in construction a comprehensive description of the characteristic of high safety standards in construction work. from the combined perspective of supervisors and experienced workers. J Safety Res. 2009; 40(6): 399-409.

4. Gao R, Chan APC, Utama WP, Zahoor H. Multilevel safety climate and safety performance in the construction industry: Development and validation of a top-down mechanism. Int J Environ Res Public Health. 2016; 13(11). art. no. 1100

5. Behm M. Linking construction fatalities to the design for con-struction safety concept. Safety Sci. 2005; 43(8): 589611.

6. Namian M, Albert A, Zuluaga CM, Behm M. Role of safety training: Impact on hazard recognition and safety risk perception. J Constr Eng Manag. 2016; 142(12)

7. Pingani L, Evansacko S, Luciano M, Del Vecchio V, Ferrari S, Sampogna $\mathrm{G}$, et al. Psychometric validation of the Italian version of the Reported and Intended Behaviour Scale (RIBS). Epidemiol Psychiatr Sci. 2016; 25(5): 485-492.

8. Allen K, Reed-Rhoads T, Terry RA, Murphy TJ, Stone AD. Coefficient alpha: An engineer's interpretation of test reliability. J Eng Educ. 2008; 97(1): 87-94.

9. Hair JF, Anderson RE, Tatham RL, Black WC. Multivariate data analysis with reading. $5^{\text {th }}$ Ed. Englewood Cliffs. NJ. USA: Prentice Hall.1998

10. Saga R, Fujita T, Kitami K, Matsumoto K. Improvement of factor model with text information based on factor model construction process. Frontiers in Artificial Intelligence and Applications 2013; 254: 222-230.

11. Seo H-C, Lee Y-S, Kim J-J, Jee N-Y. Analyzing safety behaviors of temporary construction workers using structural equation modeling. Safety Sci. 2015; 77. https://doi.org/10.1016/j.ssci.2015.03.010

12. Kim H, Kim K, Kim H. Vision-Based Object-Centric Safety Assessment Using Fuzzy Inference: Monitoring Struck-By Accidents with Moving Objects. J Comp Civ Eng. 2016; 30(4): 4015075. https://doi.org/10.1061/ (ASCE)CP.1943-5487.0000562

13. Buica G, Antonov AE, Beiu C, Pasculescu D, Remus D. Occupational health and safety management in construc-tion sector -The cost of work accidents. Quality - Access to Success; 2017: 18: 35-40. 
14. Lin S-H, Wang Z-M, Tang W-J, Liang L-H, Wang M-Z, Lan Y-J. Development of safety climate measurement at workplace: Validity and reliability assessment. Journal of Sichuan University (Medical Science Edition) 2007: 38(4): 720-724

15. Mohammadfa I, Ghasemi F, Kalatpour O, Moghimbeigi A. Constructing a Bayesian network model for improving safety behavior of employees at workplaces. Appl Ergon. 2017; 58: 35-47.

16. Mitropoulos PT, Cupido G. The role of production and team work practices in construction safety: a cognitive model and an empirical case study. J Safety Res. 2009; 40(4): 265275.

17. Ho DCK, Duffy VG, Shih HM. An empirical analysis of effective TQM implementation in the Hong Kong electronics manufacturing industry. Human Factors \& Ergonomics in Manufacturing 1999; 9(1): 125.

18. Amiri M, Ardeshir A, Fazel Zarandi MH. Fuzzy probabilistic expert system for occupational hazard assessment in construction. Safety Sci. 2017; 93: 16-28.

19. Liao P-C, Lei G, Xue J, Fang D. Influence of person-organizational fit on construction safety climate. J Manag Eng. 2015; 31(4). https://doi. org/10.1061/(ASCE)ME.1943-5479.0000257
20. Molina ML, Lloréns-Montes J, Ruiz-Moreno A. Relationship between quality management practices and knowledge transfer. J Oper Manag. 2007; 25(3): 682701

21. Rubio-Romero JC, Carrillo-Castrillo JA, Gibb A. Prevention of falls to a lower level: evaluation of an occupational health and safety intervention via subsidies for the replacement of scaffolding. Int J Inj Contr Saf Promot. 2015; 22 (1): 16-23.

22. Carrillo-Castrillo JA, Rubio-Romero JC, Onieva L, López-Arquillos A. The Causes of Severe Accidents in the Andalusian Manufacturing Sector: The Role of Human Factors in Official Accident Investigations. Human Factors and Ergonomics in Manufacturing \& Service Industries 2016; 26(1): 68-83. https://doi.org/10.1002/hfm.20614

23. Choudhry RM. Behavior-based safety on construction sites: A case study. Accid Anal Prev. 2014; 70: 14-23.

24. Fruchter R, Cavallin H. Attention and engagement of remote team members in collaborative multimedia environments Congress on Computing in Civil Engineering. Proceedings. 2011; 875-882.

25. López Arquillos A, Rubio Romero JC, Gibb A. Analysis of construction accidents in Spain 2003-2008. J Saf Res. 2012; 43(5-6): 381-388. https:// doi.org/10.1016/j.jsr.2012.07.005 